\title{
Physical mapping of 5S, 45S, Arabidopsis-type telomere sequence repeats and AT-rich regions in Achillea millefolium showing intra-chromosomal variation by FISH and DAPI
}

\author{
Magdy Hussein Abd El-Twab ${ }^{1,2}$ and Katsuhiko Kondo ${ }^{1,3}$ \\ ${ }^{1}$ Laboratory of Plant Genetics and Breeding Research, Department of \\ Agriculture, Faculty of Agriculture, Tokyo University of Agriculture, \\ Funako 1737, Atsugi City, Kanagawa Prefecture, Japan; \\ ${ }^{2}$ Department of Botany and Microbiology, Faculty of Science, \\ Minia University 61519, El-Minia City, Egypt \\ ${ }^{3}$ Author for correspondence: (k3kondo@nodai.ac.jp) \\ Received May 23, 2007; accepted June 17, 2009
}

\begin{abstract}
Achillea millefolium L. collected in Altai, Russia showed $2 \mathrm{n}=54$ as a hexaploid chromosme number. The interphase and metaphase chromosomes had FISH signals and DAPI bands: FISH yellow-colored signals of the $5 \mathrm{~S}$ and $45 \mathrm{~S}$ rDNA and the Arabidopsis-type telomeres were obtained after the hybridization of the biotin labbelled probes of the 5S, pTa71 and the Arabidopsistype telomere sequence repeats. The 5S rDNA signals consisted of 11 yellow-color signals at the secondary constriction of the satchromosomes, two large interstitial signals on the long arm of two chromosomes, and very small four signals on the long arm of four chromosomes. The interphase nucleus showed 11 deep and two faint yellow color signals of $5 \mathrm{~S}$ rDNA sites. Eleven yellow color signals of the 45S rDNA sites were detected on the short arm of 11 chromosomes. The Arabidopsis-type telomere signals were located on the terminal region on the both arms of chromosomes, while some were located far from the chromosome arm on the external part of the satellites in the sat-chromosomes, three terminal signals in some chromosomal arms one signal instead of two in the other chromosomes. DAPI-positive bands were found on interphase nucleus and 42 chromosomes, of which ten were terminal on both arms, four had two bands on a single arm, two had two bands on centromeric and terminal regions and 26 had single bands on a single arm. The 11 signals of the $5 \mathrm{~S}$ and $45 \mathrm{~S}$ rDNA sites and the the Arabidopsis-type telomere signals and DAPI bands performed variation in size and intensity
\end{abstract}

KEYWORDS: Achillea millefolium, Arabidopsis-type telomere sequence repeats, DAPI, FISH, 5S rDNA, 45S rDNA

Achillea millefolium L., yarrow or thousandleaf: grassy balds, roadsides, disturbed areas; common, April-November. The species has been taxonomically treated with several subspecies and varieties such as $A$. millefolium ssp. millefolium; A. millefolium ssp. lanulosa (Nuttall) Piper; A. lanulosa Nuttall; A. millefolium; A. millefolium var. millefolium; A. millefolium var. occidentalis DC. (Weakly 2007). It is often used as traditional and folklore medicine (Pleah et al. 2002). The name Achillea millefolium has been applied to a complex of barely distinguishable species or subspecies, which have evolved by polyploidy. This has been resulted in some confusion in nomenclature. The name Achillea was used to mean A. millefolium, without differentiation between the different subspecies (Ross 2003). Achillea is a variable temperature herb with a very wide range of potential actions and uses. This is associated with its unusually wide range of active constituents, including essential oils, sesquiterpene lactones, flavonoids, alkaloids, polyacetylenes, sterols, phenolic acids, coumarins, and tannins. Achillea can contain $0.2-1 \%$ essential oil, which may contain $0-50 \%$ chamazulene (Ross 2003).

Polyploidy is an intriguing phenomenon in plants that has provided an important pathway for evolution and speciation of the species (Soltis and Soltis 2000). The widespread occurrence of polyploidy has been attributed to the potential of polyploid species to adapt to a wider range of habitats and survive better in unstable climates than their diploid progenitors. The types of changes in chromosomes/genomes that have occurred during species evolution, has a direct impact on the basic and applied botany and to the aims of plant researchers and breeders in understanding genome evolution and genetics makes this area worthy of further investigation (Heslop-Harrison 2000). In nature, closely related taxa might make crosshybrids, which play an important role in the chromosome evolution of the species (Kondo et al. 1994).

Therefore, several chromosome analyses of polyploidy Chrysanthemum and its allied genera have been carried out extensively in the Japanese, Chinese and Russian species (e.g., Tanaka et al. 1989; Abd El-Twab and Kondo 2003a,b, 2006, 2007a; Hoshi et al. 2003; Kondo et al. 1994; Zhmyleva and Kondo 2006; Pellicer et al. 2007).

Fluorescent banding methods such as 4-6-diamidino2-phenylindole (DAPI) to determine the A-T (AdenineThymine) rich segments along the chromosomes of various plants could provide more details and critical chromosomal data for phylogenetic relationships of species (Sumner 1990; Hizume et al. 1997). Therefore, the fluorochrome banding techniques have been employed to some chromosome complements of Japanese and Chinese species of Chrysanthemum sensu lato (Kondo et al. 1995; Khaung et al. 1995; Abd El-Twab and Kondo 2003a).

In higher eukaryotes, rDNA's are organized into two distinct gene classes of the major rDNA cluster encoding $45 \mathrm{~S}$ rDNAs; and the minor rDNA cluster encoding $5 \mathrm{~S}$ 
rDNA. The minor rDNAs are usually found in loci that are separate from those of the major rDNAs, and is repeated in tandem comprises a highly conserved 120-nucleotid coding sequence and non-transcribed spacer and not involved in the nucleolus formation (Inafuku 2000). Another highly conserved sequence is found at the physical ends of chromosomes of nearly most of plant species. Multiple copies of a motif similar to the seven nucleotide unit TTTAGGG are added by an enzyme, telomerase, incorporating an RNA template, and function in stabilizing the chromosome ends and enabling semi conservative replication of the DNA up to the telomerase added region (Fuchs and Schubert 1995).

Non-radioactive in situ hybridization is a valuable, effective and safety method for studying the chromosomal distribution of DNA sequences and copy numbers at different sites, and to follow evolutionary changes in their physical organization in the genome (Harrison and Heslop-Harrison 1995; Kondo et al. 1996; Abd El-Twab and Kondo 2008). As the pioneer among molecular cytogenetics techniques, fluorescence in situ hybridization (FISH) allows identification of specific sequences in a structurally preserved cell, in metaphase or interphase. This technique, based on the complementary doublestranded nature of DNA, hybridizes labeled specific DNA (probe). The probe, bound to the target, will be developed into a fluorescent signal. The fact that the signal can be detected clearly, even when fixed in interphase, improves the accuracy of the results (Mühlmann 2002). FISH became a valuable method for studying the chromosomal distribution of DNA sequences and copy numbers at different sites, and to follow evolutionary changes in their physical organization in the genome (Harrison and Heslop-Harrison, 1995). FISH makes chromosomes of plant species providing the information of molecular characters of nucleolar organizing region (HeslopHarrison et al. 1991; Kondo et al. 1996; Kondo and Abd El-Twab 2002; Abd El-Twab and Kondo 2003b, 2008). In plants, physical localization of the tandemly repeated genes encoding the 5S ribosomal RNA (5S rDNA) and 18S-5.8S-25S ribosomal RNA genes (45S rDNA) and Arabidopsis type of telomere repeats has provided a group of valuable chromosome landmark markers. The classes of rDNA and telomeres are a major type of repetitive sequence in the higher plant genome. The chromosomal localization of the 5S, 45S rDNA and Arabidopsis-type telomere sequence repeats via FISH in the chromosome complements of several species in Chrysanthemum sensu eato was reported (Kondo et al. 1996; Khaung et al. 1997; Honda et al. 1997; Abd El-Twab et al. 1999; Abd El-Twab and Kondo 1999, 2002, 2003a,b, 2004, 2007a, b, 2008).

In our laboratory, Achillea millefolium is used as both pollen and ovule parent to produce the artificial inter- and intra-generic hybrids among the group species in Chrysanthemum sensu lato. Therefore, in the present work, we aimed to investigate the chromosome number and the physical location of the 5S, 45S rDNA sites and telemoric repeats by FISH and AT regions by DAPI on the somatic chromosomes of A. millefolium, which is considered a very important and valuable landmark for identifying specific chromosomes of this species in the artificial produced hybrids.

\section{Materials and Methods}

The plants used in this study were Achillea millefolium (sn: Russ-1, 2 and 3) were cultivated in the Laboratory of Plant Chromosome and Gene Stock, Graduate School of Science, Hiroshima University.

Chromosome preparation Following Kondo et al. (1996) growing root tips were collected and pretreated in 0.002 M 8-hydroxyquinolin at $18^{\circ} \mathrm{C}$ for $1.5 \mathrm{~h}$. They were fixed in 1:3 of glacial acetic acid and $95 \%$ ethanol at $4^{\circ} \mathrm{C}$ for 2 h. Fixed roots were excised and washed in distilled water many times to remove the fixative. Five to ten tips $2-5 \mathrm{~mm}$ long each from root tips were placed in $1.5 \mathrm{ml}$ microcentrifuge tube containing the enzymatic buffer of 5\% cellulase (Yakult), 2\% pectolyase Y-23 (Kikkoman). They were incubated at $37^{\circ} \mathrm{C}$ for $20 \mathrm{~min}$, and then, their soft meristematic tissues were washed in distilled water to remove the enzymatic solution and were squashed in $45 \%$ acetic acid. The cover-slip was removed by the dry-ice freezing method and the preparation was dried at room temperature.

DAPI fluorescent staining after FISH Following Abd El-Twab and Kondo (2003a), the slides were removed their hybridized probe, the slides after FISH were heated at $85^{\circ} \mathrm{C}$ for $10 \mathrm{~min}$ in washing buffer $(0.1 \mathrm{XSSC}, 0.5 \%$ SDS), washed in $100 \%$ alcohol for $1 \mathrm{~h}$, then air-dried at room tempreature and finally applied DAPI. The slides were washed in MacIlvain buffer at $\mathrm{pH} 7.0$ at room temperatur for $30 \mathrm{~min}$ and they were dropped $50 \mu 1$ of 0.1 $\mathrm{mg} / \mathrm{ml}$ Actinomycin D (Sigma) dissolved in MacIlvain buffer at $\mathrm{pH}$ 7.0. They were washed in MacIlvain buffer at $\mathrm{pH} 7.0$ at room temperature for ten min, and were stained in $10 \mu \mathrm{g} / \mathrm{ml}$ DAPI dissolved in MacIlvain buffer at $\mathrm{pH} 7.0$ at room temperature for $30 \mathrm{~min}$. The slides were washed in MacIlvain buffer at $\mathrm{pH} 7.0$ at room temperature for 10 min and were mounted with coverslips using a drop of $50 \%$ glycerol. The slides were observed on an Epifluorescence microscope using UV filter (UV-2A; Nikon).

Ribosomal DNA probes: 5 S rDNA probe The 5S rDNA probe was produced by the polymerase chain reaction (PCR) method as described by Hizume (1993) and Abd El-Twab and Kondo (2002).

$45 S$ rDNA probe The probe of pTa71 (45S rDNA) consisted of a $9 \mathrm{~kb}$ Eco RI fragment of rDNA derived from Triticum aestivum L. (Gerlach and Bedbrook 1979), which was recloned into $\mathrm{pUC1} 19$ plasmid. It was comprised of the coding sequence for the $18 \mathrm{~S}, 5.8 \mathrm{~S}$ and $26 \mathrm{~S}$ genes 
and the non-transcribed spacer sequences.

Probe of the Arabidopsis-type telomere sequence repeats The probe of the Arabidopsis-type telomere sequence repeats was synthesized by using the polymerase chain reaction (PCR). PCR was carried out in the absence of template using the primers (TTTAGGG) ${ }_{5}$ and (CCCTAAA) (Schwarzacher and Heslop-Harrison 1991; Cox et al. 1993; Abd El-Twab and Kondo 2007a). Each $50 \mu 1$ reaction mixture included $50 \mathrm{mM}$ Tris- $\mathrm{HCl}, \mathrm{pH} 9.0\left(25^{\circ} \mathrm{C}\right), 50 \mathrm{mM}$ $\mathrm{KCl}, 0.1 \mathrm{mM}$ EDTA, $0.1 \%$ (v/v) Triton X-100, $1.25 \mathrm{mM}$ $\mathrm{MgCl} 22.5$ units of Taq polymerase (TOYOBO), $200 \mu \mathrm{M}$ each dNTP and 200nM each primer. Temperature cycling was performed as follows: The first step of one cycle each took for $1 \mathrm{~min}$ at $94^{\circ} \mathrm{C}$, and $30 \mathrm{sec}$ at $55^{\circ} \mathrm{C}$ and $1 \mathrm{~min}$ at $72^{\circ} \mathrm{C}$; the second step of 35 cycles each for $30 \mathrm{sec}$ at $94^{\circ} \mathrm{C}$, $30 \mathrm{sec}$ at $55^{\circ} \mathrm{C}$ and $1 \mathrm{~min}$ at $72^{\circ} \mathrm{C}$; and the final step for 3 min at $72^{\circ} \mathrm{C}$. The product was purified by PCI (phenol:ch loroform:isoamilalcohol $=25: 24: 1)$ treatment, CIA treatment and ethanol precipitation method. The oligonucleotide purified, the Arabidopsis-type telomere sequence repeats were dissolved in $5 \mu 1$ of TE buffer $(10.0 \mathrm{mM}$ Tris. $\mathrm{Cl}$ at $\mathrm{pH}$ 8.0 and 1.0mM EDTA at $\mathrm{pH} 8.0$ ). The concentration of the products was measured with the absorption meter (Ultrospec 3000). Then, the Arabiropsis-type telomere sequence repeats were used for labeling reaction.

Labeling of the probes The probes were labeled with biotin-14-dATP nick translation kit (Gibco BRL), labeling of each probe was carried out according to the manufacturer's protocols.

The procedure of FISH and detection of the probe followed the methods described by Abd El-Twab and Kondo (1999). FISH that fluoresced the yellow-color was visualized by FITC after the hybridization with the biotin labeled probes and red-color was visualized by the counter stain of propidium iodide (PI). Fluorescence signals were examined with an epifluorescence microscope with Nikon B-2A filter cassette and microphotographs were taken on CCD camera (Pixera Pengium 600CL). Analysis of hybridization signals and karyogrames were produced using Adobe Photoshop 7.

\section{Results And Discussion}

Achillea millefolium collected during the field trip of 2004 in the Altai Mountains, Russia showed the chromosome number of $2 n=54$ (hexaploid). The interphase and metaphase chromosomes in A. millefolium had FISH signals and DAPI bands (Figs. 1 and 2). Respective interphase nucleus had 11 yellow-color signals of 45S rDNA and positive DAPI bands (Fig. 1A and B). Each interphase nucleus showed four nucleolus cavities that had 14 yellow color signals of the 45S rDNA (Fig. 2A) instead of 11 (Fig. 1A), that showed two signals inside the left nucleolus cavity, five signals on the border of the other three nucleolus cavities, and the other four signals were found outside the cavities in the interphase nucleus. Eleven yellow-color signals of $45 \mathrm{~S}$ rDNA were detected on the short arm of 11 chromosomes hybridized with the biotin labeled probe of pTa71 (Fig. 1D and Fig. 2C). Eleven yellow signals of 5S rDNA at the sites of sat-chromosomes, two large intersticial signals on the long arm of two chromosomes, and very small four signals (not visible constantly in all plates) on the long arm of four chromosomes, which hybridized with the biotin labeled probe of the 5S rDNA (Fig. 1E). Only Eleven strong and two faint yellow color signals of $5 \mathrm{~S}$ rDNA sites in the interphase (Fig. 1C) were detected after hybridization with the probe. The plate of metaphase chromosome complement counterstained-red by PI was DAPI-positive bands on 42 chromosomes, of which ten chromosomes had terminal bands on both arms; four chromosomes had two bands on a single arm; two chromosome had two bands centromeric and terminal; 26 chromosomes have single positive DAPI bands on a single arm (Fig. 1E and F). The signals of the Arabidopsis-type telomere sequence repeats were yellow color on the terminal region on both arms of the metaphase chromosomes. The sat-chromosomes showed the signal of the Arabidopsis-type telomere sequence repeats far from the chromosome arm on the external part of the satellite, some chromosomal arms showed three terminal signals and the others showed one signal instead of two that were hybridized with the somatic chromosomes, as appeared in the karyogram of the chromosome complement, which showed chromosome pairing that had similar terminal telomere of yellow color signals (Fig. 2D and E), which hybridized with the biotin labeled probe of the PCR amplified telomeric repeats.

Achillea millefolium L. has been taxonomically wellstudied with several different synonymous names such as A. lanulosa Nutt., A. magna auct., A. millefolium subsp. borealis (Bong.) Breitung, A. millefolium subsp. lanulosa (Nutt.) Piper, A. millefolium subsp. millefolium, A. millefolium var. occidentale DC. (see Germplasm Resources Information Network (GRIN) Taxonomy for Plants: http://www.arsgrin.gov/).

Achillea millefolium has been subjected to intensively investigate its chromosome numbers such as $2 \mathrm{n}=18$, diploid (Daniela 1997), 2n=27, triploid (Maffei et al. 1986), $2 n=36$, tetraploid (eg. Hommel and Wieffering 1979; Löve and Löve 1982), $2 \mathrm{n}=45$, pentaploid (Androshchuk and Kostinenko 1981), 2n=54, hexaploid (eg., Morton 1977; Arohonka 1982; Kuzmanov et al. 1989; Huber and Baltisberger 1992; Druskovic and Lovka 1995), 2n=72, heptaploid (Magulaev 1982). Additionally, the species showed also several different haploid sets such as $\mathrm{n}=9$, $18,22,27,29,36$ and 58) and aneuploid chromosome numbers such as $2 n=34,35$ and 44) (Gervais 1977; Keil and Stuessy 1977; Pireh and Tyrl 1980; Gupta and Gill 1981; Morton 1981). but very little in chromosome character in the most standard references.

Achillea lanulosa which was considered a synonym of 

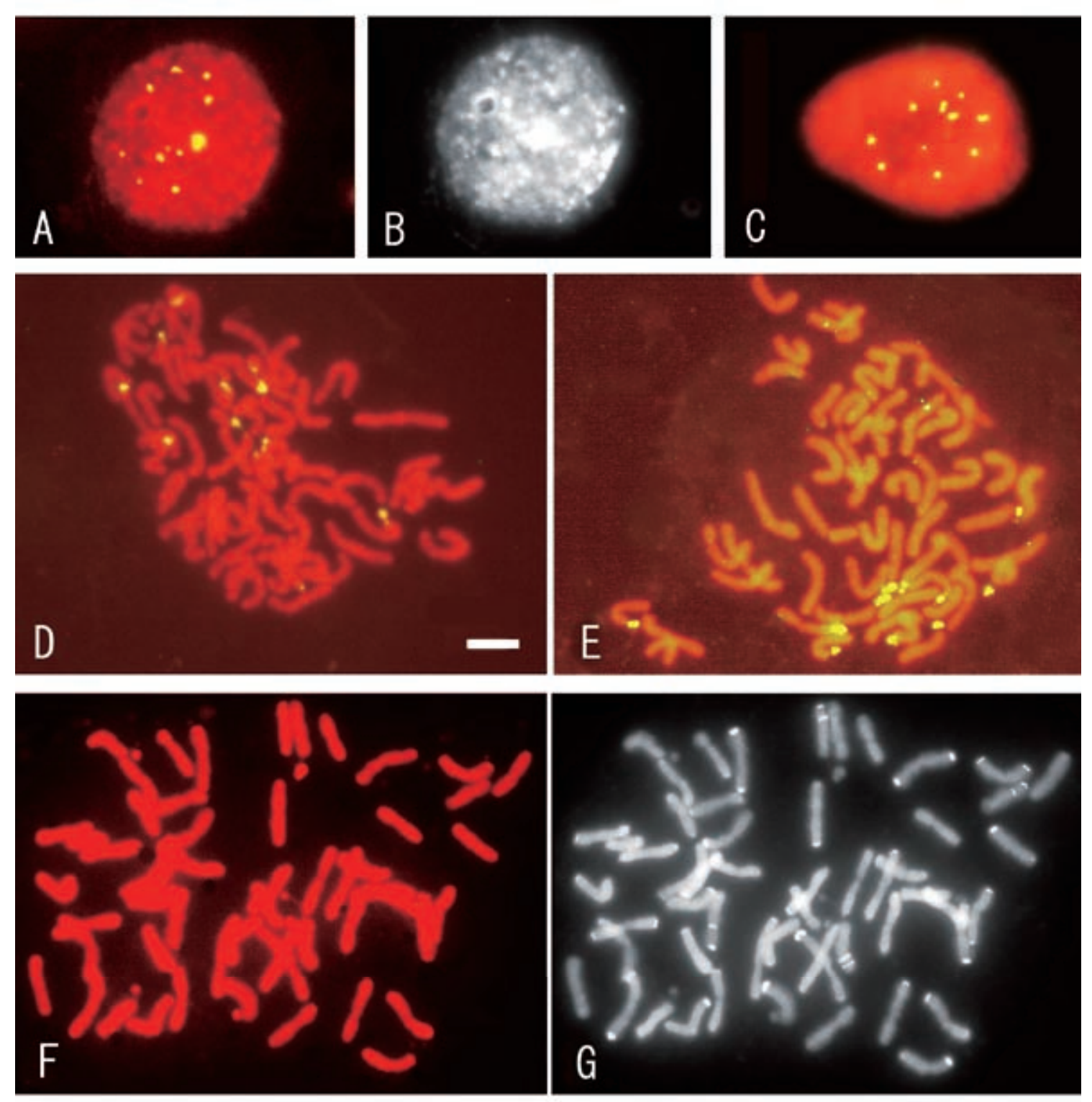

Fig. 1. Interphase (A-C) and metaphase chromosomes (D-G) have FISH signals (A-E) and DAPI bands (B and $\mathrm{G}$ ) in A. millefolium (sn: Russ-1, 2004). Yellow-color was fluoresced and visualized by FITC after the hybridization with the biotin labeled probes and red-color was visualized by the counter stain of PI. A-B. Same interphase nucleus has eleven yellow-color signals of 45S rDNA sites (A) and positive DAPI bands (B). C. Eleven strong and two faint yellow color signals of 5S rDNA sites hybridized with the biotin labeled probe of the PCR amplified 5S rDNA. D. Eleven yellow-color signals of the 45S rDNA sites that hybridized with the biotin labeled probe of pTa71. E. Eleven yellow-color signals of 5S rDNA sites at the same sites of the NOR regions of the sat-chromosomes, two large intersticial signals on the long arm of two chromosomes, and very small four signals on the long arm of four chromosomes, which hybridized with the biotin labeled probe of the $5 \mathrm{~S}$ rDNA. F-G.Same plate of metaphase chromosome complement counterstained-red by PI (F) and DAPI-positive $(\mathrm{G})$ bands on 42 chromosomes, of which ten chromosomes have terminal bands on both arms; four chromosomes have two bands on a single arm; two chromosome have two bands centromeric and terminal; 26 chromosomes have single prositive DAPI bands on a single arm. Bar $=10 \mu \mathrm{m}$.

A. millefolium regarding morphological variation in leaf shape among different populations (Gurevitch 1991). The chromosome number reported for A. lanulosa was tetraploid with $2 \mathrm{n}=36$ (Löve and Löve 1980, 1982) while it was the haploid chromosome set with $n=36_{\text {I }}$ (Keil and Stussy 1977) and $n=18_{\text {II }}$ (Löve and Löve 1980). However, the chromosome report of another synonym A. magna could not be found. It was interesting to find that differences in chromosome number between the A. millefolium subspecies were often accompanied by important chemical differences (Ross 2003), which, in their turn, may lead to differences in temperature, actions, and uses. The percentage of chamazulene and the general composition of the essential oil fraction vary greatly with the chromosome number of the plant material. The tetraploid plants had sesquiterpenes, mainly chamazulene (ca $25 \%$ ), while the hexaploid plants of $A$. millefolium ssp. millefolium had no chamazulene (Ross 2003). However, it could not be supported simply that the other species and subspecies of A. millefolium were just synonyms of the species. The 

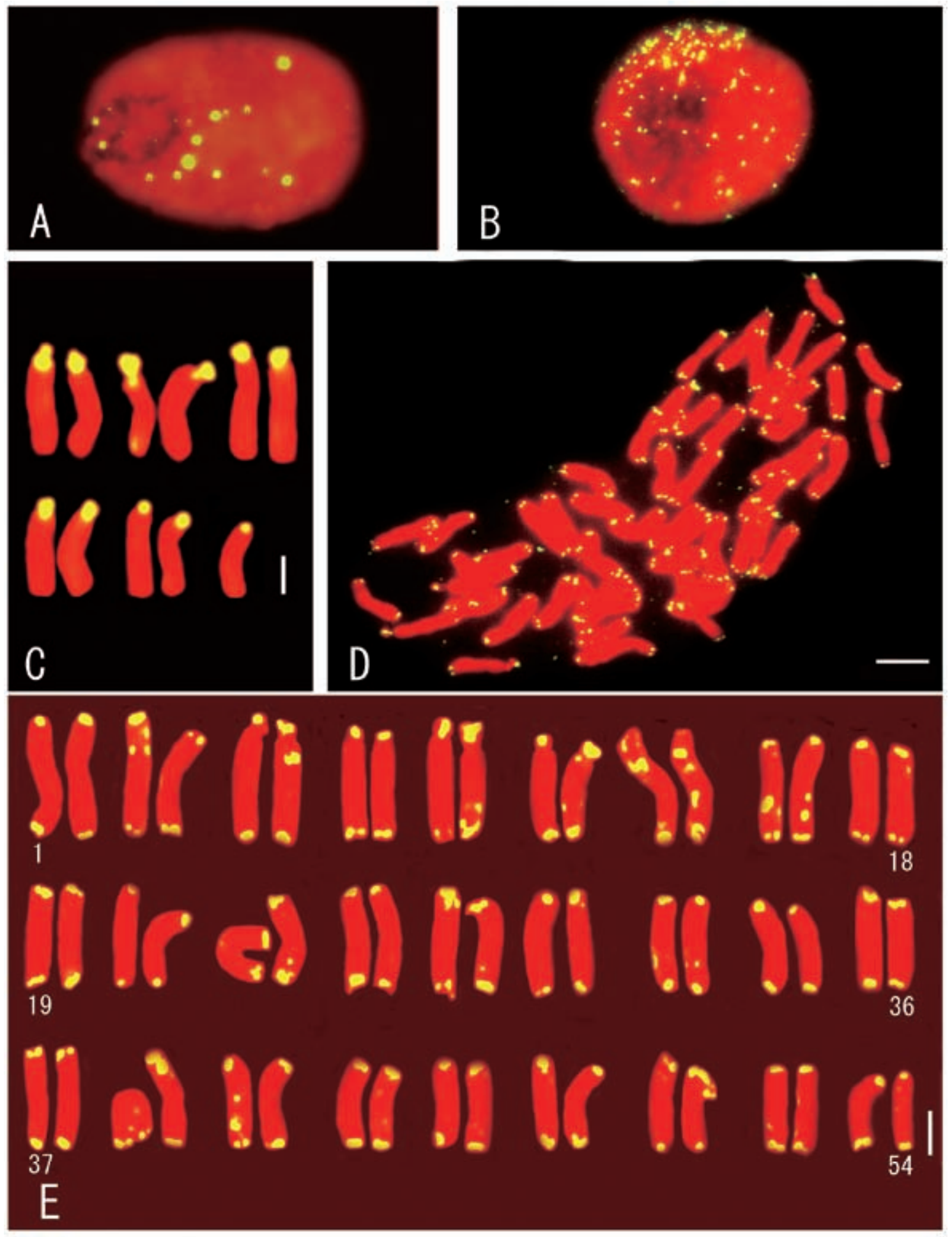

Fig. 2. FISH yellow color signals on mitotic interphase (A-B) and metaphase (C-E) chromosomes in $A$. millefolium (sn: Russ-2, 2004). Yellow-color was fluoresced and visualized by FITC after the hybridization with the biotin labeled probes and red-color was visualized by the counter stain of PI. A. Interphase nucleus showing four nucleoli cavities; fourteen signals instead of eleven, which show two signals inside the left nucleolus cavity, five signals on the border of the other three nucleoli cavities, and the other four signals outside the cavities. B. Yellow color signals of the telomeres that hybridized with the biotin labeled probe of the PCR amplified telomeric probe. C. Eleven signals of the 45S rDNA on the short arm of eleven chromosomes that hybridized with the biotin labeled probe of pTa71. D. Terminal yellow signals of the telomeres that hybridized with the biotin labeled probe of the PCR amplified telomeric probe. E. Karyograme of the chromosome complement showing the chromosome pairing that has similar terminal telomere signals. Bar $=10 \mu \mathrm{m}$. 
chromosome numbers in the species were correlated with variation of natural products with respect to the ploid level (Ross 2003).

Divergence and speciation are often accompanied by reorganization in the chromosomes. However, the karyotypes of Chrysanthemum species and related genera are highly conservative and it is difficult for them to be differentiated closely related species, such as species of the same ploidy level by karyotyping (Tanaka et al. 1989). In contrast, rDNA FISH gives much higher resolution for detecting chromosome variations among closely related species. Our present results and other studies (Kondo et al. 1996; Khaung et al. 1997; Honda et al. 1997; Abd El-Twab and Kondo 2003b, 2007b, 2008) have shown that within the genus Chrysanthemum and closely related genera the number and positions of major rDNA sites on chromosomes varied among the species in Chrysanthemum sensu lato. This variation should have a phylogenetic implications, since the more similar rDNA FISH patterns are likely to be in the most closely related taxa (Abd El-Twab and Kondo 2003b). The distribution patterns of rDNA loci among the chromosomes vary markedly among Chrysanthemum sensu lato.

In diploid species the number of major $45 \mathrm{~S}$ rDNA sites typically ranged between one and four pairs (e.g., Abd ElTwab and Kondo 2003b). The highest \% of FISH signal number of the $45 \mathrm{~S}$ rDNA per chromosome complement among the wild species of Chrysanthemum was $44.4 \%$ in the diploid D. lavandulifolia while the highest \% among the wild hexaploid species was $33.3 \%$ in C. occidentalijaponense (Abd El-Twab and Kondo 2003b) and that was varied approximately $25.9-35.2 \%$, in the wild C. zawadekii indicating genome complex (Abd El-Twab and Kondo 2006) and was the highst $55.5 \%$ in the cultivars of Chrysanthemum (Abd El-Twab and Kondo 2004). In the present study signal numbers were not even number but odd number and percentages of the FISH signal number of the $45 \mathrm{~S}$ rDNA were approximately $20.4 \%$ (Table 1 ), also the 11 signals of the $5 \mathrm{~S}, 45 \mathrm{~S}$ rDNA sites and the telomeric signals and DAPI bands showed variation in size and intensity indicating this $A$. millefolium studied up to date might have a complex genome.

Since, a prediction of chromosomal locations of satellites would be that closely related satellite sequences

Table 1. FISH signals of $45 \mathrm{~S}$ rDNA sites in somatic chromosomes of several species in Chrysanthemum sensu lato up to date

\begin{tabular}{|c|c|c|c|c|}
\hline \multirow{3}{*}{ Species } & \multirow{3}{*}{$2 n$} & \multicolumn{2}{|c|}{ FISH signals of pTa71 } & \multirow{3}{*}{$\begin{array}{l}\text { References of } 45 \mathrm{~S} \text { rDNA } \\
\text { sites in Chrysanthemum }\end{array}$} \\
\hline & & \multicolumn{2}{|c|}{ Of 45S rDNA sites } & \\
\hline & & No. & $\%$ & \\
\hline Achillea millefolium & 54 & 11 & 20.4 & present study \\
\hline Ajania remotipinna & 18 & 4 & 22.2 & Abd El-Twab and Kondo 2007b \\
\hline Chrysanthemum boreale & 18 & 6 & 33.3 & Honda et al. 1997 \\
\hline C. horaimontanum & 18 & 2 & 11.1 & Abd El-Twab and Kondo 2003 \\
\hline C. japonicum & 18 & 4 & 22.2 & Kondo et al. 1996 \\
\hline C. lavandulifolium & 18 & 8 & 44.4 & Khaung et al. 1997 \\
\hline C. chanetii & 36 & 8 & 22.2 & Abd El-Twab and Kondo 2007b \\
\hline C. indicum (Japan) & 36 & 8 & 22.2 & Khaung et al. 1997 \\
\hline C. indicum (China) & 36 & 12 & 33.3 & Abd El-Twab and Kondo 2003 \\
\hline C. wakasaense & 36 & 8 & 22.2 & Kondo et al. 1996 \\
\hline \multirow[t]{2}{*}{ C. yoshinaganthum } & 36 & 10 & 27.8 & Khaung et al. 1997 \\
\hline & & 4 & 11.1 & Honda et al. 1997 \\
\hline \multirow[t]{2}{*}{ C. occidentali-japonense } & 54 & 10 & 18.5 & Abd El-Twab and Kondo 2003 \\
\hline & & 18 & 33.3 & Abd El-Twab and Kondo 2003 \\
\hline C. vestitum & 54 & 10 & 18.5 & Abd El-Twab and Kondo 2003 \\
\hline C. grandiflorum $\mathrm{cv}$. & 54 & 30 & 55.6 & Abd El-Twab and Kondo 2004 \\
\hline 'Shuho-no-chikara' & & & & \\
\hline C. grandiflorum cv. 'Golden Shark' & 54 & 12 & 22.2 & Abd El-Twab and Kondo 2004 \\
\hline C. grandiflorum cv. 'Monaco' & 52 & 7 & 13.5 & Abd El-Twab and Kondo 2004 \\
\hline C. grandiflorum cv. 'Sei Alpes' & 54 & 12 & 22.2 & Abd El-Twab and Kondo 2004 \\
\hline C. morii & 72 & 10 & 13.8 & Abd El-Twab and Kondo 2003 \\
\hline Leucanthemella linearis & 18 & 6 & 33.3 & Abd El-Twab and Kondo 2007a \\
\hline Nipponanthemum nipponicum & 18 & 2 & 11.1 & Abd El-Twab and Kondo 2007a \\
\hline
\end{tabular}


showed similar chromosome distributions. Closely related satellite repeats occupy adjacent regions of the chromosomal DNA. Such, topological constraints might arise from either functional restrictions or from mode of origin, one from the other (Lohe and Roberts 1988). It also helps to clarify genetic maps and to assign linkage groups to physically marked chromosomes. By comparing the rDNA FISH patterns identified homologous chromosomes among the species. It was found that $A$. millefolium in the present study had different shapes and sizes of the of the $5 \mathrm{~S}$ and $45 \mathrm{~S}$ rDNA sites on the NOR regions of the satchromosomes, which were two groups; first group consists of eight chromosomes have large region of yellow color signals of the $45 \mathrm{~S}$ rDNA sites, and extended outside the short arms of the chromosomes, the second group consists of three chromosomes have three large $45 \mathrm{~S}$ rDNA attached with chromosomes. Based on the number and place of the FISH signals of the $45 \mathrm{~S}$ rDNA sites in the inthphase nucleoli we could speculate that various numbers of the FISH yellow color signals of the $45 \mathrm{~S}$ rDNA sites in the interphase nuclei might due to extension of the satchromosome inside the nucleus due to active sites. The signals inside or around the nucleolus border might indicate gene activity and active sat-chromosomes, while the signals outside the nucleoli cavities might indicate that the sites of $45 \mathrm{~S}$ rDNA are inactive gene in the interphase nucleus. The co-localization of the $5 \mathrm{~S}$ and $45 \mathrm{~S}$ rDNA sites gave us now a prelimanry outline about the relation of the Chrysanthemum sesu lato, since two major groups of $5 \mathrm{~S}$ rDNA were given to be able to divide the species into at least two or three genetically different groups by using the probe of 5S rDNA amplified from $C$. boreale and $C$. vestitum and two main features such as the interstitial signals of the 5S site (Abd El-Twab and Kondo 2002) and the co-localized $5 \mathrm{~S}$ and $45 \mathrm{~S}$ sites on different chromosomes in this study and else where (Abd El-Twab and Kondo 2004, 2007a). This study may be extended to several different materials in Chrysanthemum sensu lato using the probe of $5 \mathrm{~S}$ rDNA to justify our speculation about the taxonomic and genetical relationships among the species group of Chrysanthemum sensu lato, with special references to the Japanese and Chinese species.

Studies on origin and chromosome constitutions of the native polyploid species of Chrysanthemum sensu lato may contribute to satisfactory phylogenetic and taxonomic treatment of species relationships. In the course of evolution, the species genome appears to have undergone structural reorganization and recombination and, thus, formed unique chromosome complement characteristics as observed here. Knowledges of the relative physical locations and the number of multicopy rDNA gene loci are important and useful both for the construction of physical maps of chromosomes and for phylogenetic studies. Our data of the FISH provided useful information on the presence of the $5 \mathrm{~S}$ and $45 \mathrm{~S}$ rDNA sites, telomere and AT-rich regions by DAPI as well as their relative positions on chromosomes of the species, which are considered a very important landmark for identifying specific chromosomes of this species in the artificial produced hybrids in our laboratory.

World populations of Achillea millefolium and its synonyms may be very important for investigating the genome characterization, changes, interaction and evolution among the collections of the world wide distributed and medicinally important species.

ACKNOWLEDGMENTS. This study was supported by the Grant-in-Aid for Scientific Research Program A (1) 19255004 of the Japan Society for the Promotion of Science (Representative: Katsuhiko Kondo), The first and Second National Bioresource Project "Chrysanthemum sensu lato" of Ministry of Education, Culture, Sports, Science and Technology, "MEXT" of Japan (Representative up to 2008: Katsuhiko Kondo). The senior author was supported by the Invitation Fellowship for Research in Japan (Longterm: L09550) in 2009 of Japan Society for the Promotion of Science

\section{Literature CiTED}

Abd El-Twab, M. H. and Kondo, K. 1999. Identification of nucleolar organizing regions and parental chromosomes in $F_{1}$ hybrid of Dendranthema japonica and Tanacetum vulgare simultaneously by fluorescence in situ hybridization. Chrom. Sci. 3: 59-62.

Abd El-Twab, M. H., Kondo, K. and Hong, D. 1999. Isolation of a particular chromosome of Ajania remotipinna in a chromosome complement of an artificial $\mathrm{F}_{1}$ hybrid of Dendranthema lavandulifolia X Ajania remotipinna by use of genomic in situ hybridization. Chrom. Sci. 3: 21-28.

Abd El-Twab, M. H. and Kondo, K. 2002. Physical mapping of $5 \mathrm{~S}$ rDNA in chromosomes of Dendranthema by fluorescence in situ hybridization. Chrom. Sci. 6: 13-16.

Abd El-Twab, M. H. and Kondo, K. 2003a. Rapid genome changes after inter specific hybridization between Dendranthema indica X $D$. vestita identified by fluorescent in situ hybridization and 4, 6-diamidino-2-phenylindole. Chrom. Sci. 7: 77-81.

Abd El-Twab, M. H. and Kondo, K. 2003b. Physical mapping of 45S rDNA loci by fluorescent in situ hybridization and Evolution among polyploid Dendranthema species. Chrom. Sci. 7: 71-76.

Abd El-Twab, M. H. and Kondo, K. 2004. Identification of mutation and homologous chromosomes in four cultivars of Dendranthema grandiflora by physical mapping of $5 \mathrm{~S}$ and $45 \mathrm{~S}$ rDNA using fluorescence genomic in situ hybridization. Chrom. Sci. 8: 81-86.

Abd El-Twab, M. H. and Kondo, K. 2006. FISH physical mapping of 5S, 45S and Arabidopsis-type telomere sequence repeats in Chrysanthemum zawadskii showing intra-chromosomal variation and complexity in nature. Chrom. Bot. 1: 1-5.

Abd El-Twab, M. H. and Kondo, K. 2007a. FISH physical mapping of $5 \mathrm{~S}$ rDNA and telomere sequence repeats identified a peculiar chromosome mapping and mutation in Leucanthemella linearis and Nipponanthemum nipponicum in Chrysanthemum sensu lato. Chrom. Bot. 2: 11-17.

Abd El-Twab, M. H. and Kondo, K. 2007b. Rapid genome reshuffling induced by allopolyploidy in $\mathrm{F}_{1}$ hybrid in Chrysanthemum sensu lato (Ajania-Dendranthema). Chrom. Bot. 2: 1-9.

Abd El-Twab, M. H. and Kondo, K. 2008. Visualization of genomic relationships in allotetraploid hybrids between Chrysanthemum lavandulifolium X C. chanetii by fluorescence in situ hybridization and genomic in situ hybridizarion. Chrom. Bot. 3: 19-25.

Androshchuk, A. F., Iic L. and Kostinenko, D. 1981. Chromosome numbers of the genus Achillea L. Certain species cultivated 
in botanical gardens. Ukrajins'kyj Bot. Žurnal 38: 53-57. Arohonka, T. 1982. Chromosome counts of vascular plants of the island Seili in Nauvo, southwestern Finland Turun Yliopiston Julkaisuja: Sarja A II, Biol. Geogr. 3: 1-12.

Cox, A. V., Bennett, S. T., Parokonny, A. S., Kenton, A., Callimassia, M. A. and Bennett, M. D. 1993. Comparison of plant telomere locations using a PCR-generated synthetic probe. Ann. Bot. 72: 239-247.

Daniela, I. 1997. IOPB chromosome data 11 Newslett. Int. Organ. Pl. Biosyst. (Oslo) 26/27: 13-14.

Druskovic, B. and Lovka, M. 1995. IOPB chromosome data 9 IOPB Newsl. 24: 15-19.

Fuchs, J. and Schubert, I. 1995. Localization of seed protein genes on metaphase chromosomes of Vicia faba via fluorescence in situ hybridization. Chrom. Res. 3: 94-100.

Gerlach, W. L. and Bedbrook, J. R. 1979. Cloning and characterization of ribosomal RNA genes from wheat and barley. Nucl. Aci. Res. 7: 1869-1885.

Gervais, C. 1977. Cytological investigation of the Achillea millefolium complex (Compositae) in Quebec. Can. Jour. Bot. 55: 796-808.

Gupta, R. C. and Gill, B. S. 1981. In Chromosome number reports LXXI. Taxon 30: 514.

Gurevitch, J. 1991. Sources of Variation in Leaf Shape Among Two Populations of Achillea lanulosa. Genetics: 385394.

Harrison, G. E. and Heslop-Harrison, J. S. 1995. Centromeric repetitive DNA sequences in the genus Brassica. Theor. Appl. Genet. 90: 157-165.

Heslop-Harrison, J. S. 2000. Comparative Genome Organization in Plants: From Sequence and Markers to Chromatin and Chromosomes. Plt. Cell 12: 617-635.

Heslop-Harrison, J. S., Schwarzacher, T., Anamthawat-Jonson, K., Leich, A. R., Shi, M. and Leich, I. J. 1991. In situ hybridization with automated chromosome denaturation. Technique 3: 109-116.

Hizume, M. 1993. Chromosome localization of 5S rDNA genes in Vicia faba and Crepis capillaris. Cytologia 58: 417-421.

Hizume, M., Kondo, K., Ge, S., and Yang Q. 1997. Fluorescence chromosome banding pattern with chromomycin $\mathrm{A}_{3}$ in Picea crassifolia and P. wilsonii collected in Qinghai, China. In: Conservation Biology in Plants Common to Japan and China (ed: K. Kondo), Nishiki Print Co. Ltd. Pp. 50-59.

Honda, Y., Abd El-Twab, M. H., Ogura, H., Kondo, K., Tanaka, R. and Shidahara, T. 1997. Counting sat-chromosome numbers and species characterization in wild species of Chrysanthemum sensu lato by fluorescence in situ hybridization using pTa71 probe. Chrom. Sci. 1: 77-81.

Hommel, P. W., and Wieffering, J. H. 1979. IOPB chromosome number reports LXIII. Taxon 28: 277-278.

Hoshi, Y., Kondo, K., Korobkov, A. A., Tatarenko, I. V., Kulikove, P. V., Verkholat, V. P., Ghontcharov, A., Ogura, H., Funamoto, T., Kokubugata, G., Suzuki, R. and Matoba, H. 2003. Cytological study in the genus Artemisia L. (Asteraceae) from Russia. Chrom. Sci. 7: 83-89.

Huber, W. and Baltisberger, M. 1992. IOPB chromosome data 4 IOPB Newsl. 18/19: 6-8.

Inafuku, K., Nabeyama, M., Kikuma, Y., Saitoh, J., Kubota, S., and Kohno, S. 2000. Chromosomal location and nucleotide sequence of 5S ribosomal DNA of two cyprinid species (Osteichthyes, Pisces). Chrom. Res. 8: 193-199.

Keil, D. J. and Stuessy, T. F. 1977. Chromosome counts of Compositae from Mexico and the United States. Am. Jour. Bot. 64: 791-798.

Khaung, K., Kondo, K. and Tanaka, R. 1997. Physical mapping of rDNA by fluorescent in situ hybridization using pTa71 probe in three tetraploid species of Dendranthema. Chrom. Sci. 1: 25-30.

Khaung, K., Kondo, K., Tanaka, R. and Nakata, M. 1995. A comparison of fluorescence banding patterns in Dendranthema indicum collected in Japan and China. La Chromosomo II-79-80: 2746-2753.

Kondo, K. and Abd El-Twab, M. H. 2002. Analysis of interageneric relationships Sensu stricto among the members of Chrysanthemum sensu lato by using fluorescence in situ hybridization and genomic in situ hybridization. Chrom. Sci. 6: 87-100.

Kondo, K., Honda, Y. and Tanaka, R. 1996. Chromosome marking in Dendranthema japonica var. wakasaense and its closely related species by fluorescence in situ hybridization using rDNA probe. La Kromosomo II-81: 27852791.

Kondo, K., Khaung, K. K., Tanaka, R. and Nakata, M. 1995. Fluorescent banding patterns in hexaploid Dendranthema occidentali-japonense and D. vestitum. La Kromosomo II-79-80: 2739-2745.

Kondo, K., Tanaka, R., Hong, D., Hizume, M., Yang, Q. and Nakata, M. 1994. A chromosome study of Ajania and its allied genera in the Chrysantheminae, the Anthemideae, the Compositae in Chinese highlands. Pp. 1-13 Tanaka, Karyomorphological and cytogenetical studies in plants common to Japan and China. Hiroshima University pp. 75.

Kuzmanov, B. A., Zdravkova, M. A. and Georgieva, S. B. 1989. Variability of the Bulgarian yarrow species from the group Achillea millefolium and A. crithmifolia. 1. Morphological and karyological study. Fitologija 36: 26-43.

Lohe, A. and Roberts, P. 1988. The biology of heterochromatin. In Heterochromatin molecular and structural aspects, ed. R. H. Verma. New York, Cambridge University Press. Pp. 148-186.

Löve, A. and Löve, D. 1980. Chromosome number reports LXIX. Taxon 29: 707-709.

Löve, A. and Löve, D. 1982. IOPB chromosome number reports LXXVI. Taxon 31: 583-587.

Maffei, M., Deirino, L. and Codignola, A. 1986. Numeri cromosomici per la flora Italiana: 1064-1069. Inf. Bot. Italia. 18: 153-158.

Magulaev, A. Y. 1982. The number of chromosomes of the species of Asteraceae, Caryophyllaceae and Plantaginaceae of the North Caucasus Biologicheskie Nauki, 11 (227): 74-79.

Morton, J. K. 1981. Chromosome numbers in Compositae from Canada and the U.S.A. Bot. Jour. Linn. Soc. 82: 357-368.

Morton, J. K. 1977. A cytological study of the Compositae (excluding Hieracium and Taraxacum) of the British Isles. Watsonia 11: 211-223.

Mühlmann, M. 2002. Molecular cytogenetics in metaphase and interphase cells for cancer and genetic research, diagnosis and prognosis. Application in tissue sections and cell suspensions. Genet. Mol. Res. 1: 117-127.

Peleah, E., Pisova, M. and Ciobanu, V. 2002. Essential oil composition of Achillea millefolium L. and Achillea coarctata Poir. from Moldova. Koryo, Terupen oyobi Seiyu Kagaku ni kansuru Toronkai Koen Yoshishu, 46:266.

Pellicer, J., Garcia, S., Garnatje, T., Dariimaa, S., Krobkov, A. A. and Valles, J. 2007. Chromosome numbers in some Artemisia (Asteraceae, Anthemideae) species and genome size variation in its subgenus Dracunculus: Karyological, systematic and phylogenetic implications. Chrom. Bot. 2: 45-53.

Pireh, W. and Tyrl, R. J. 1980. Cytogeography of Achillea millefolium in Oklahoma and adjacent States. Rhodora 80: 361-367.

Ross, J. 2003. Combining Western Herbs and Chinese Medicine. Greenfields Press Bristol, Pp: 899.

Schwarzacher, T., and Heslop-Harrison, J. S., 1991. In situ hybridization to plant telomeres using synthetic oligomers. 
Genome 34: 317-323.

Soltis, P. S. and Soltis, D. E. 2000. The role of genetic and genomic attributes in the success of polyploids, Proc. Natl. Acad. Sci. USA 97: 7051-7057.

Sumner, A. T. 1990. Chromosome banding. Unwin Hyman, London, pp. 434.

Tanaka, R., Kawasaki, S., Yonezawa, Y., Taniguchi, K. and Ikeda, H. 1989. Cytogenetic studies on wild Chrysanthemum from
China V. $\mathrm{F}_{1}$-hybrids of Chrysanthemum lavandulifolium var. sianense X Ch. boreale. Cytologia 54: 365-372.

Weakley, A. S. 2007. Flora of the Carolinas, Virginia, and Georgia, and Surrounding Areas. Dicotyledons. Part 2: pp. 68-686.

Zhmyleva, A. P. and Kondo, K. 2006. Comparison of somatic chromosomes in some species of Chrysanthemum sensu lato in Russia. Chrom. Bot. 1: 13-22. 